\title{
EDITORIAL
}

\section{Changes to manuscript requirements and website}

\author{
Liew Su May \\ Chief Editor of MFP
}

\begin{abstract}
On behalf of the Board of Editors, Malaysian Family Physician, I am pleased to announce the latest changes to our journal. These changes are in line with the journal's ongoing efforts to improve the quality of the journal, increase visibility and readership, and fulfil our overall aim, which is to act as the voice of family physicians, researchers and other members of the primary care team on clinical practice issues and research.
\end{abstract}

The first change is that we are now publishing articles online prior to the publication of the journal issue. This is our Online First section that can be seen at our website https://e-mfp.org/. We hope to improve our time to publication through this method as the journal only publishes three issues in a year. I will take this opportunity to assure authors that the board of editors will continue to work on our time to publication to ensure that your work is shared in a timely manner. However, this will require the help of all members of our fraternity as it is challenging to find reviewers for the articles.

Secondly, we have revised the content of the Information for Authors page. An article may not be able to pass screening or peer review if it does not fulfil journal requirements. We ask authors to carefully go through these guidelines so that their submitted manuscripts will be more likely to pass review. You will see that we have made this section more detailed and emphasized ethical requirements, a patient-centred focus and reporting checklists according to study design.

Our aim is not to make it more difficult to publish in the Malaysian Family Physician! We hope to make it easier for authors to publish their research by stating the requirements clearly from the start. Thank you for helping us in our efforts to improve our journal. 